\title{
A City in Anatolia; Revealing Domestic Violence in The Emergency Department in Çorum
}

Anadolu'da Bir Şehir; Çorum’da Acil Servisde Aile İçi Şiddetin Ortaya Konması

\author{
Hüseyin ÜLGER \\ Adana Şehir Hastaesi Acil Tıp Kliniği, Adana, Türkiye
}

\begin{abstract}
Aim: In this study, it was aimed to reveal the level and dimension of the violence experienced by women who applied to the emergency service with domestic violence (DV).

Method: The Severity of Violence Assessment Scale (SVAS) was performed in 176 cases who applied to emergency department and expressed them were under domestic violence.

Results: Women who were under domestic violence were evaluated according to SVAS. It was found that $3.4 \%$ were SVAS-1, 30.1\% were SVAS-2, 64.2\% were SVAS-3 according to the scale. It was reported that $67 \%$ of the emergency service applications were due to physical violence only. The level of violence and also the type of violence was changing with the educational and marital status of the cases, the person who was applying it and the type of application were also effecting the violence severity $(p<0.05)$.

Conclusion: According to the violence scale, most frequently, second and third level applications such as slap, push, punch and injuries apply to the emergency service. Early precautions should be taken and strict follow-up should be carried out for this level of violence to prevent mortality hence the situation may progress to higher levels.

ÖZET

Amaç: Bu çalışmayla acil servise aile içi şiddetle (Aişs) başvuran kadınların maruz kaldıkları şiddet düzeyi ve boyutunun ortaya konması amaçlanmıştır.

Yöntem: Aiş̧ gördüğ̈̈̈ӥ bildiren ve acil servislere başvuran 176 olgunun, Şiddetin Ciddiyetini Değerlendirme Skalast (ŞCDS) yapıldt.

Bulgular: AIŞ’e uğrayan kadınların ŞCDS göre kadınların \%3,4'ü ŞCDS-1, \%30,1'i ŞCDS-2, \%64,2'si ŞCDS-3 idi. Acil başvurularının \%67'sinin sadece fiziksel şiddet içerikli olduğu saptandı. Olguların eğitim ve medeni durumu ile şiddetin seviyesi değișmekte ve ayrıca şiddetin türü, şiddeti uygulayan kişi ve başvuru şekli de şiddeti etkilemektedir $(p<0.05)$.

Sonuç: Şiddet skalasina göre acil servise en sik tokat, itme, yumruk, yaralanma şeklinde, ikinci ve üçüncü düzeyde başvurular gerçekleşmektedir. Bu düzeydeki yaralanmaların daha üst seviyelere ilerlememesi ve mortal seyretmemesi için erken dönemde alınabilecek önlem ve sık takiple yaralanmalar azaltılabilir.
\end{abstract}

Key Words:

Domestic Violence,

Emergency Service,

Violence against women,

Intimate partner violence,

Hospital,

Scale for Evaluating the Severity of Violence.

\section{Anahtar Kelimeler:}

Aile içi şiddet,

Acil servis,

Kadına yönelik şiddet,

Eş şiddeti.

Hastane,

Siddetin Ciddiyetini

Değerlendirme Skalast.

\section{Giris}

Temel insan hakları ve özgürlüklerin ihlali olan kadına yönelik aile içi şiddet (Aİ̧̧), tüm dünyada ve ülkemizde rastlanılan en yaygın ve ciddi sorunlardan biridir (1) Gelecek nesillerin sağlığını etkileyebilecek akut sosyal problemdir. Gelenekler, kadının statüsünün düşük olması ve ekonomik özgürlüğünün olmaması, güvenlik, utanma, korku ve farkındalık eksikliği gibi pek çok nedenden dolayı şiddete maruz kalınsa bile bildirilmemektedir. Bazı toplumlarda hatta bunlar sosyal açıdan normal kabul edilmektedir (2).

Aile içi şiddet mağdurlarıyla ilk temasın sağlandığı ve sıklıkla açıklanacağı yer acil servistir. Aile içi şiddete uğrayanların doğrudan tıbbi tedavi ve bakımın sağlandığı yerdir. Çalışmamız tüm taraflar için tartışılması zor olan aile içi şiddetin acil servis düzeyinde ne kadar ciddi düzeyde yaşandığını ortaya koyması açısından önemlidir.

\section{GEREÇ ve YÖNTEM}

Çorum'da acil servise, aile içi şiddete uğradığı tespit edilen kadınlardan kayıt formu düzenlenen 176 vaka çalışmaya dahil edilmiştir. Kadınların yaş, medeni hali, öğrenim durumu, çalışma durumu, şiddet gördükten sonra ilk başvuru yeri ve şekli, maruz kalınan şiddetin türü kaydedildi. Kadına yönelik aile içi şiddet seviyesini ölçmek için Sağlık Bakanlığınca kullanılan kadına yönelik aile içi şiddet formundaki Şiddetin Ciddiyetini Değerlendirme Skalası (ŞCDS)'ndan yararlanılmış̧ır. Kadınların şikayetlerinde skaladaki en yüksek değerler alınmıştır. Buna göre;

1. Şiddet tehtidi, silahla birlikte,

2. Tokatlama, itme (yaralanma ve uzun süreli acı yok),

3. Yumruklama, tekmeleme, yaralar, kesikler ve/veya devam eden ac1,

4. Ciddi sonuçlar, yanıklar, kemik kırılması,

Correspondence: Hüseyin ÜLGER, Dr. Mithat Özsan Bulvarı Kışla Mah. 4522 Sok. No: 1 Yüreğir/ADANA E-Mail: drhuseyinulger@yahoo.com.tr Phone : +90 5336523805

Cite this article as: Ülger H. A City in Anatolia; Revealing Domestic Violence in the Emergency Department in Çorum. Phnx Med J. 2020;2(1):35-40. 


\section{Ülger}

Tablo 1: Şiddete uğrayan kadınların sosyodemografik özellikleri ve şiddet skalası

\begin{tabular}{|c|c|c|}
\hline Sosyodemografik özellikler & Sayı (n) & $\%$ \\
\hline \multicolumn{3}{|l|}{ Yaş grupları (yıllar) } \\
\hline $15-24$ & 43 & 24.4 \\
\hline $25-34$ & 80 & 45.5 \\
\hline $35-44$ & 35 & 19.9 \\
\hline $45+$ & 18 & 10.2 \\
\hline \multicolumn{3}{|l|}{ Eğitim durumu ${ }^{a, \dagger}$} \\
\hline Okuryazar değil & 13 & 7.4 \\
\hline Okuryazar & 5 & 2.8 \\
\hline İlkokul & 91 & 51.8 \\
\hline Ortaokul & 40 & 22.7 \\
\hline Lise & 19 & 10.8 \\
\hline Üniversite & 8 & 4.5 \\
\hline \multicolumn{3}{|l|}{ Medeni durumu $^{\ddagger}$} \\
\hline Evli & 160 & 90.9 \\
\hline Bekar & 10 & 5.7 \\
\hline Dul & 2 & 1.1 \\
\hline Boşanmış & 4 & 2.3 \\
\hline \multicolumn{3}{|l|}{ Çalışma durumu ${ }^{\text {a }}$} \\
\hline Çalışıyor & 42 & 23.9 \\
\hline Çalışmıyor & 134 & 76.1 \\
\hline \multicolumn{3}{|l|}{ 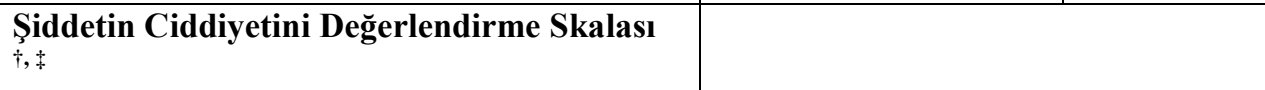 } \\
\hline ŞCDS-1 (tehdit) & 6 & 3.4 \\
\hline ŞCDS-2 (tokat, itme) & 53 & 30.1 \\
\hline ŞCDS-3 (yumruk, tekme, yara, kesik) & 113 & 64.2 \\
\hline ŞCDS-4 (yanık, kemik kırılması) & 1 & 0.6 \\
\hline ŞCDS-5 (organlarda kalıcı yaralanmalar) & 0 & 0 \\
\hline ŞCDS-6 (silahla yaralanma) & 3 & 1.7 \\
\hline
\end{tabular}

( $\mathrm{a}$ : çalışma durumu ile eğitim durumu arasına $\mathrm{p}<0.05,{ }^{\text {: }}$ ŞCDS ile eğitim durumu arasında $\mathrm{p}=0.003$, ${ }^{\ddagger}:$ ŞCDS ile medeni durum arasında $\mathrm{p}=0.000$ )

5. Baş ve/veya iç organlarda kalıcı yaralanmalar,

6. Silah kullanımı, silah ile yaralama şeklinde derecelendirilmektedir (3).

Çalışmamızda Helsinki deklerasyon prensiplerine uyulmuştur. $\mathrm{Bu}$ makalenin yayınlanması için tüm katılımcılardan bilgilendirilmiş onam alındı. İstatistiksel veri analizleri SPSS 15.0 paket programı yardımıyla değerlendirilmiştir. Tanımlayıcı tipte düzenlenmiş olan çalışmanın bulguları sayı ve yüzde olarak ifade edilmiş, analizlerde Ki-kare testi kullanılmıştır. İstatistiksel önemlilik için $\mathrm{p}<0.05$ kabul edilmiştir.

\section{BULGULAR}

Çalışmaya dahil edilen 176 kadın olgunun yaş ortalaması $32.33 \pm 11.21$ (15-80) idi.

Tablo 1'de yaş aralıkları, eğitim seviyesi, medeni hali ve çalışma durumu gibi sosyodemografik özellikleri ile şiddetin ciddiyeti arasındaki ilişki verilmektedir. Tablolardaki iki paramete arasındaki anlamlı ilişki çeşitli sembollerle ifade edilmektedir. 
Tablo 2. Kadınların uğradıkları şiddetin özellikleri

\begin{tabular}{|c|c|c|}
\hline Özellikler & Sayı (n) & $\%$ \\
\hline \multicolumn{3}{|l|}{ Şiddetin yeri } \\
\hline $\mathrm{Ev}$ & 161 & 91 \\
\hline Sokak & 12 & 6.8 \\
\hline İş yeri & 3 & 2.2 \\
\hline \multicolumn{3}{|l|}{ Şiddetin türü* } \\
\hline Fiziksel (F) & 118 & 67 \\
\hline Duygusal (D) & 4 & 2.3 \\
\hline Cinsel (C) & 2 & 1.1 \\
\hline$(F)+(D)$ & 38 & 21.6 \\
\hline$(\mathrm{F})+(\mathrm{C})$ & 1 & 0.6 \\
\hline$(F)+(D)+(C)$ & 1 & 0.6 \\
\hline$(\mathrm{F})+(\mathrm{D})+$ Ekonomik & 6 & 3.4 \\
\hline$(\mathrm{F})+(\mathrm{D})+(\mathrm{C})+$ Ekonomik & 6 & 3.4 \\
\hline \multicolumn{3}{|l|}{ Şiddeti uygulayan kişi * } \\
\hline Eşi & 156 & 88.6 \\
\hline Çocuğu & 1 & 0.6 \\
\hline Kayınvalide & 1 & 0.6 \\
\hline Kayınpeder & 2 & 1.1 \\
\hline Anne, baba & 6 & 3.4 \\
\hline Eşi, kayınvalide, kayınpeder & 2 & 1.1 \\
\hline Diğger (dayı, gelin, ağabey) & 8 & 4.6 \\
\hline \multicolumn{3}{|l|}{ Başvuru şekli *** } \\
\hline Darp & 163 & 92.7 \\
\hline Kesici, delici aletle yaralanma & 5 & 2.8 \\
\hline İntihar girişimi & 5 & 2.8 \\
\hline Doğum (18 yaş altı) & 2 & 1.1 \\
\hline Anksiyete & 1 & 0.6 \\
\hline \multicolumn{3}{|l|}{ Başvuru yeri } \\
\hline Acil servis & 153 & 86.9 \\
\hline Emniyet (güvenlik, polis, jandarma) & 23 & 13.1 \\
\hline
\end{tabular}

Tablo 2'de kadınların uğradıkları şiddetin özellikleri verildi. Çalışmamızda başvuru şekli, şiddeti uygulayan kişi, şiddetin türü, medeni hali, eğitim ve çalışma durumu ile şiddet derecesi arasında anlamlı ilişki saptand1.

Şiddet gören kadınların eğitim düzeyi ile çalışma durumunu karşılaştırdığımızda; yüksekokul mezunu olan kadınların \%62,5'i çalışmakta \%37,5'i ise çalışmamaktadır; diğer tüm öğrenim düzeylerinde çalışma yüzdesi, çalışmama yüzdesinden düşüktür $(p=0.039)$.
Kadınların eğitim düzeyi ile şiddet şekli ve yeri, başvuru şekli arasında anlamlı farklılık saptanmamıştır. Eğitim düzeyi ile "Şiddetin ciddiyetini değerlendirme skalası" karşılaştırıldı̆̆ında, genel olarak eğitim düzeylerinde en yüksek oranda ŞCDS-3 "Yumruklama, tekmeleme, yaralar, kesikler, devam eden acı" olarak saptand1. Yüksekokul mezunu olan kadınlarda bu oran \%37,5'ti. Yüksekokul mezunlarında ŞCDS-4 “ciddi sonuçlar, yanıklar, kemik kırılması" ve ŞCDS-6 "Silah kullanımı, silah ile yaralama" durumu \%12,5 idi. ŞCDS-1 "Silah ile birlikte şiddet tehtidine" ise ilk ve ortaokul mezunları maruz kalmıştı $(\mathrm{p}=0.003)$. 
Evli kadınların ağırlıklı olarak ŞCDS-2,3’e, bekar olanların ŞCDS-1,2,6'ya ayrıca evli kadınların dul ve boşanmış kadınlarda saptanmayan ŞCDS-4 ve ŞCDS-6 'ya da maruz kaldıkları saptand 1 ( $\mathrm{p}=0.001)$.

Evlilerin çok yüksek oranda darp ile kesici aletle yaralanma, özkıyım girişimi ve anksiyete ile bekarların ise darp, kesici alet yaralanma ve istenmeyen gebelik öyküsü, boşanmış olanlar ise darp ve özkıyım girişimi ile başvuru şekli değişmekteydi $(\mathrm{p}=0.000)$.

Evli kadınların şiddetin her türü ile karşılaştı̆̆ 1 , bekarların fiziksel ve cinsel şiddete uğradığı, boşanmış olanların ise çoğunlukla fiziksel şiddete uğradığı saptand 1 ( $\mathrm{p}=0.000)$. Evlilerin çoğunlukla eşlerinden, daha az olarak kayın valide ve kayın pederlerinden, bekarların ise anne ve babalarından, dul olanların da kendi çocukları ve gelinlerinden, boşanmış olanlarınsa eski eşlerinden şiddet gördükleri ortaya kondu $(\mathrm{p}=0.000)$.

Kadınların \%81,3'ü çocuk sahibi ve \%5,1'i şiddet gördüğü sırada hamiledir. Hamile iken şiddet gören 9 kadının özelliklerini incelediğimizde; Kadınların \%88,9 unun daha öncesinde şiddet hikayesi vard1 ve hepsi eşinden şiddet gördüğünü belirtmiştir. "Şiddetin ciddiyetini belirleme skalasına" göre \%22,2 si tokatlama itme, \%77,8 i yumruk, tekme yaralama şeklindeki şiddete maruz kalmıştır. Hamile kadınların uğradıkları şiddet türü ve şiddetin ciddiyeti hamile olmayan kadınlarla karşılaştırıldığında aralarında anlamlı fark olmadığı saptanmıştır $(\mathrm{p}=0.546, \mathrm{p}=0.909)$.

\section{TARTISMA}

Dünyada milyonlarca kadının, toplumda ve aile içinde şiddete maruz kaldıkları bilinmektedir. Aile içi şiddete farklı toplumlarda \%10-69 arasında değişen sıklıkta izlenmektedir. Ülkemizdeki sonuçlar da bu aralığın içinde yer almakta ancak bazı bölgelerde fiziksel şiddete uğrama oranının yüksek olduğu belirlenmiştir (4). Şiddet mağdurlarının ciddi bir kısmı hiçbir kuruma başvuru yapmamaktadır. Bir kısmı adli makamlara başvurup rapor için gelmektedir. Çoğunlukla olan kısmı ise çalışmamızda da ortaya konduğu gibi \%86,9 ile ilk başvuru yeri acil servisdir. Genel popülasyonda aile içi şiddet görenler, yaralanma sonucunda yatış oranı ve acil servise başvuru oranı beklenenden dört kat fazladır (5). İzmir örneğinde acile başvuranların \%69,8'inde fiziksel şiddet saptanmıştır (3). Çalışmamızda ise aile içi şiddet ile başvuran bayanların $\% 67$ 'si sadece fiziksel tipte şiddet başta olmak üzere duygusal, ekonomik ve cinsel olarak tüm şiddet türlerine uğrayan olgular mevcut. Acil servislere başvuru oranının yüksek olması şiddet mağdurlarının kendileri için acil servisleri sığınma kapıları olarak görmesi ve hızlı erişimin olması olabilir.

Vakalarımızın çoğu ikinci ve üçüncü seviyede yaralanmalar; tokat, yumruk sebebiyle ve daha nadir olarak kesici delici aletle yaralanma, ateşli silah ile yaralanma, anksiyete, yanık ve intihar girişimi şeklindedir. Acil servise gögüs ağrısı ile başvuran bayanlar üzerine yapılan çalışmada, \%21,6 sında aile içi şiddet hikayesi olduğu tespit edilmiştir. Genç yaşdaki bu kişiler anksiyete veya depresif semptomlarla acil servise başvurabilmektedir (6). Bunun nedeni evli bayanlar evliliklerini kurtarmak veya çeşitli sebeplerle düşme sonucu oldu gibi daha farklı gizleme çabaları bunda etkili olabilir. Çalışmamızda evli, bekar ve boşanmış bayanların medeni durumlarına göre başvuru şekilleri değişmektedir.

Sağlık personelininde aile içi şiddet mağdurlarını tespit etmede yeterli bilgi ve beceriye sahip olup olmaması da önemli bir etkendir (7). Hastanemizde sağlık personeli üzerinde yapılan çalışmada \%68,6'sının kadına yönelik aile içi şiddet konusunda hiçbir eğitim almadığı ortaya konmuştur (8). Ülkemizde acil personeli üzerinde yapılan diğer bir çalişmada sağlık çalışanının \%92,7 sinin aile içi şiddeti sorgulamadığ tespit edilmiştir (9). Ayrıca acil sağlık personelinin aile içi şiddet konusunda bilgi almak ve soru sormak için yeterli donanımının olmadığı görülmektedir (10). Yapılan çalışmalar ülkemizde sağlık personelinin eğitilmesi ihtiyacını açıkça göstermektedir. Halkımızın ve sağlı personelinin eğitilmesiyle birlikte tanımlayıcı çalışmaların genişletilerek tüm olguların kayıt altına alınmasıyla aile içi şiddetin gerçek istatistiksel değerlerine ulaşması mümkün olabilecektir. Acil sağlık personeli olan paramedikler için aile içi şiddeti tanıma ile bakım ve destek almalarını yönlendiren klavuz oluşturulmuştur (11). Bu uygulamalar diğer sağlık çalışanları için yaygınlaştırılabilir.

Çalışmamız aile içi şiddetin acil servis düzeyinde, yaşanan boyutunu ortaya koyması açısından büyük önem arzetmektedir. Çünkü şiddete uğrayan kadınların sosyo-demografik ve şiddet özellikleri incelendiğinde yapılan çalışmalar sağlık ocağı düzeyinde daha çok birinci basamak sağlık kurumları üzerinden, adli ve psikiyatrik olarak değerlendirilmiştir $(2,4)$. Ayrıca dahil edilen araştırma gruplarının farklı olması çalıșmamızlada objektif kıyas imkânı ortaya koymamıza engel oluşturmaktadır.

Çalışmamızda eğitim düzeyi yüksek kadınların diğer öğrenim düzeyindeki kadınlara göre anlamlı oranda çalışma yüzdesinin yüksek bulunmuştur. Kişilerin eğitim düzeylerinin artmasıyla birlikte yaşamın herhangi bir döneminde maruz kalınan şiddet yaygınlığının azaldığı ve çalışan kadınların diğer kadınlara göre korunaklı olduğu bilinmektedir (12). Şiddete uğrayan kadınların çoğunluğunun ilkokul mezunu olması bunu desteklemektedir. Ancak eğitimli iş imkanına sahip kadınların azlığına rağmen çalışmamızda şiddet seviyesine göre değerlendirdiğimizde bunun böyle olmadığını gördük. Şiddetin ciddiyetini belirleme skalasına göre yüksek okul mezunlarının daha çok ŞCDS-3,4,6'ya, ilköğretim mezunlarının ise ŞCDS-1'e maruz kalmaktadır. Çalışmamızla iş imkanına sahip yüksek öğrenim düzeyindeki kadınların ilkokul mezunlarına göre aile içi şiddete daha az maruz kalmalarına rağmen şiddeti daha ağır yaşadıkları ortaya kondu. Bunun nedeni 


\section{Phnx Med J. March, Volume 2 No 1}

ekonomik durumu iyi ve eğitim düzeyi yüksek evli kadınların, kendilerine olan özgüven ve ekonomik özgürlüğünden dolayı karşı tarafa cevap vererek, karş1 durmalarından dolayı, daha ciddi şiddete maruz kalmaları ile açıklanabilir. Ya da şiddete uğramış yüksek okul mezunu kadınlar toplum önünde küçük düşeceği endişesiyle sağlık kuruluşlarına başvurmaktan kaçınabilirler. İlkokul mezunlarının şiddetin ciddiyetine göre yüksek okul mezunlarına göre hafif düzeyde kalması şiddeti uygulayan kişilerin, eğitim düzeyi düşük ve çalışmayan kadınların tehdit ile sindirildiği sonucuna varılabilir.

Çalışmamızla evli kadınların şiddetin her türü ile karşılaştığı, bekarların fiziksel ve cinsel şiddete uğradığ1, boşanmış olanların ise çoğunlukla fiziksel şiddete uğradığı ortaya kondu. Evli kadınların şiddet skoru genel tablo ile uyumlu iken evli olanlara göre bekarların ve dul-boşanmış bayanların şiddet skoru düşük olması çalışmamızın dikkat çekici sonuçlarındandır.

Hamilelik sırasında uygulanan şiddet ile ilgili farklı sonuçlar ifade edilmektedir (13). Çalışmamızda aile içi şiddete uğrayanların \%5,1'i şiddet gördüğü sırada hamiledir. Acile başvuru sırasında gebelik durumu izmir örneğinde de aynı oranda tespit edilmiştir (3). Hamile olan ile olmayan arasında çalışmamızda şiddet skoru açısından anlamlı farklılık saptanmamıştır.

Aile içi şiddete uğrayanlarda fiziksel şiddet skoru 5,40 kat diğer gruplara göre yüksek olduğu ortaya konmuştur (14). İzmir örneğinde Şiddetin Ciddiyetini Değerlendirme Skalasına göre \%19,6'si ŞCDS-2 ve \%64'ü ŞCDS-3'tür (3). Çalışmamızda ise şiddet skalasına göre \%30,1 i ŞCDS-2 ve \%64,2 si ŞCDS-3 idi. Aile içi şiddet mağdurlarının fiziksel şiddet sonucunda en sık baş, yüz ve boyunu içeren kafa bölgesinden ve buna ek olarak kas-iskelet sistemine ait yaralanmalar şeklindedir (15). Fiziksel şiddet sonucunda en sik ikinci ve üçüncü seviyede şiddet skalası ile uyumu kadına yönelik şiddetin acil servis düzeyinde ne kadar ciddi düzeyde yaşandığını ortaya koyması açısından önemlidir.

Çalışmamızda \%21,6 fiziksel şidddet ve duygusal şiddet birlikteği fiziksel şiddetin diğer şiddet türleriyle beraberliği ile de dikkat çekici düzeydedir. Bir ailede bir türde şiddet yaşanıyorsa, genellikle bu diğer şiddet türlerinin de yaşandığına dair bir işaret olabileceği fikrini desteklemektedir $(15,16)$.

İzmir örneğinde \%90,3 ile olay evde ve \%74,3 ile kendi eşinden şiddet gördüğü tespit edilmiştir (3). Serinken ve arkadaşları \%59,9 ile olayın evde ve \%33 ile kendi eşlerinden şiddet gördüğünü belirtmektedir (16). Çalışmamızda olay \%91,5 ile evde ve \%88,6 ile kendi eşleri tarafından gerçekleştirildiği tespit edildi. Çalışmamızda eşi boşanmış kadınların eski eşleri, dul olanların kendi çocukları ve/veya gelinleri, bekarların ise kendi anne babaları tarafından şiddete maruz kaldıkları tespit edildi. Bu da kadına şiddet uygulayan kişilerin, çoğunlukla bilinmeyen, tanınmayan yabancılardan çok, kadının bildiği, tanıdığı, güvendiği erkekler olduğu ve en güvenli mekanlarında etkilendikleri görüşünü desteklemektedir (15).

İzmir örneğinde yaş ortalaması 33.36'dır (3). Denizli örneğinde yaş ortalaması 31,7 ve \%87,9'u 15-45 yaş arası bayanlardır (15). Ankara örneğinde yaş ortalaması 32,9 idi. Kadın konukevi hizmetine ilişkin bu araştırmada kadınların \%57,1'inin kadına yönelik şiddet nedeniyle konukevine başvurduğu ve \%83,3’ünün 20-45 yaş arasında oldukları belirlenmiştir (17). Çalışmamızda ise şiddete uğrayanların yaş ortalaması 32,33 ve \%89,8'i 15-45 yaş arası reprodüktif dönem bayanlardır. Tarihsel olarak uluslararası sağlık kuruluşları kadını bağımsız ihtiyaçları olan birey olmalarından ziyade nüfus artışını kontrol etmek ve çocukların hayatlarını kurtarmak amaçlı ilgilenmişlerdir (18). Genç yaş grubundaki bu kadınların sorunlarını, günümüz medeni çağda gözardı edemeyiz.

Aile içi şiddet ile acil servisimize başvuran hastaların tedavisini sadece fiziksel yaraları üzerinden değil. Aynı zamanda etkilenen duygu durum bozuklukları için psikolojik destek ile birlikte acil servis düzeyinde multidisipliner yaklaşım içinde olmalıyız. Nitekim kayıt formu düzenlenen vakaların hastanemizin psikologlarınca takipleri yapılmış, kayıtları tutulmuştur. Yasal mevzuatlar çerçevesinde sorunlarına imkanlar nispetinde çözüm yolları sağlanmıştır. Şiddet ortamından uzaklaştırmak için kadın konukevlerinde kalmaları sağlanmıştır. Bu sosyal sorunun çözümünü için acil servis düzeyinde şiddetin ciddiyetini değerlendirme skalasına göre ölüme kadar yaralanmalara yol açmadan erken dönemde önleyici çalışmalar ve takip yapılabilir.

\section{SONUÇ}

Özellikle fiziksel şiddet başta olmak üzere duygusal, ekonomik ve cinsel aile içi şiddet, şiddetin her türü ile acil servislerdedir. Evli kadınların bekar dul ve boşanmışlara göre şiddet oranı daha yüksek seyretmektedir. İş imkanına sahip yüksek öğrenim düzeyindeki kadınların ilkokul mezunlarına göre aile içi şiddete daha az maruz kalmalarına rağmen şiddet skalasına göre şiddeti daha ağır yaşadıkları ortaya konmuştur. Aile içi şiddet, Şiddetin Ciddiyetini Değerlendirme Skalasına göre büyük çoğunluğunu tokatlama, yumruklama, yaralar şeklinde ikinci ve üçüncü seviyededir. Sonuç olarak ikinci ve üçüncü seviyedeki bu hedef kitlenin şiddet düzeyinin artmamasi ve ölümle sonuçlanan durumların önlenmesi için risk altındaki grupları sıkı takip etmeliyiz. 


\section{Ülger}

\section{KAYNAKLAR}

1. Krug EG, Mercy JA, Dahlberg LL, Zwi AB. The world report on violence and health. Lancet 2002; 360:1083-8.

2. Şahin EM, Yetim D, Öyekçin DG. Rate of intimate partner violance against woman and attitudes of woman towards violence in Edirne Turkey. Cumhuriyet Medical Journal 2012;34:23-32.

3. Kılıççığlu DB, Buran CF, Küçük ZS. Forensic medical analysis of the domestic violence against women attempts to the emergency department: İzmir. Case. Journal of Human Sciences 2016;13(3), 4764-4779.

4. Arslan MM, Yarımoğlu B, Çekin N. The evaluation of intimate violance cases attended to Adana branch of council of forensic medicine. Turkiye Klinikleri J Foren Med 2005;2:39-43.

5. Ahmad I, Ali PA, Rehman S, Talpur A, Dhingra K. Intimate partner violence screening in emergency department: a rapid review of the literature. J Clin Nurs. 2017 Nov;26(21-22):3271-3285.

6. Coll-Vinent B, Martí G, Calderón S, Martínez B, Céspedes F, Fuenzalida C. Domestic violence against women patients seen with chest pain in the emergency department Semergen. 2019 Jan -Feb;45(1):23-29.

7. Kandemir Ö, Kurçer MA, Özdemir B. Experience of their knowledge levels and practice on suffered persons on domestic violence of medical staff in Viranşehir town, Şanlıurfa Turkey. J Foren Med 2010;7:13-20.

8. Duman NB, Büyükgöneç L, Güngör T. Perception of violence against woman among health care proffessionals and affecting factors. The journal of Gynecology-Obstetrics and Neonatology 2016; 13(4).

9. Vonkeman J, Atkinson PR, Fraser J. Do emergency department staff use a current domestic violence documentation tool or other forms of intimate partner violence documentation in patient records? Canadian Journal of Emergency Medicine, 2017; May19:66

10. Taylor JA. Bruised apples: violence against women in the education sector. Occup Environ Med. 2019 jan;76(1):1-2.

11. Sawyer S, Coles J, Williams A, Williams B. Paramedics as a New Resource for Women Experiencing Intimate Partner Violence.J Interpers Violence. 2018 Apr 1:886260518769363.

12. Hofner MC, Python NV, Martin E. Prevalence of victims of violence admitted to An Emergency Department. Emerg Med J 2005;22:4815 .

13. Karaoglu L, Celbis O, Ercan C. Physical, emotional and sexual violence during pregnancy in Malatya, Turkey. European Journal of Public Health 2006 ; 16:149-56.

14. Park CW, Lee SH, Choi DY, Yang HY. Victimization Characteristics and Severity of Physical Injury by Domestic Violence. Korean J Fam Pract. 2018;8(2):244-251.

15. Serinken M., Şengül C, Karcıŏlu Ö. Violence against woman: analysis of emergency department presentations. Turkish Journal of Emergency Medicine 2007;7:163-6.

16. Foa EB, Cascardi M, Zoellner LA, Feeny NC. Psychological and environmental factors associated with partner violence. Trauma, Violence and Abuse 2000; 1: 67-91.

17. Çiltaş Ç, Var Çalık E. Research On Violence Against Women And Servıce From Women's Shelter House: Example Of Ankara, Türkiye Sağlık Bilimleri ve Araştırmaları Dergisi, 2(1), 2019, 13-23.

18. Kothari CL, Rohs T, Davidson S, Kothari RU, Klein C, Koestner A, et al. Emergency Department Visits and Injury Hospitalizations for Female and Male Victims and Perpetrators of Intimate Partner Violence. Advances in Emergency Medicine Volume 2015, Article ID 502703, 11 pages. 